\title{
Midiatização empresarial: propostas de interação a partir de um canal televisivo de marca'
}

\section{Fábia Pereira Lima}

- Mestre em Comunicação Social - Interações Midiáticas pela Pontifícia Universidade Católica de Minas (PUC Minas)

- Especialista pelo curso Gestão Estratégica de Marketing da PUC Minas

- Graduada em Comunicação Social - habilitação em Relações Públicas pela mesma instituição

- Foi professora nos cursos de Comunicação Social das Faculdades Integradas do Oeste de Minas (FADOM), período 2005-2006, da Universidade Federal de Minas Gerais (UFMG), em 2006, e da PUC Minas, em 2008

- É professora no curso de Relações Públicas da Fabrai/Anhanguera

- Pesquisadora do grupo de pesquisa Comunicação no contexto organizacional: aspectos teórico-conceituais (PUC Minas/CNPq) e consultora na área de Planejamento de Comunicação Organizacional

- fabialima@gmail.com

1 Este trabalho deriva da pesquisa desenvolvida no mestrado em Comunicação Social e apresentada na dissertação intitulada Midiatização Empresarial: estratégias de legitimação e interlocução a partir de um canal televisivo de marca, defendida na Faculdade de Comunicação e Artes da Pontifícia Universidade Católica de Minas Gerais (PUC Minas), no dia 11 de fevereiro de 2009, sob a orientação da Profa. Dra. Ivone de Lourdes Oliveira. 
Resumo

O trabalho busca, por meio da análise de um canal televisivo de marca - o Canal Oi -, compreender o fenômeno da midiatização e seus reflexos na maneira como as empresas se relacionam com a sociedade na contemporaneidade. Busca também perceber como o discurso organizacional, neste processo, torna-se impregnado de traços do interlocutor com quem pretende se relacionar e da realidade sócio-cultural.

PALAVRAS-CHAVE: MIDIATIZAÇÃO • DISCURSO ORGANIZACIONAL • CULTURA CONTEMPORÂNEA

\section{Abstract}

The work strives, through analysis of a brand TV channel - Canal Oi -, to comprehend the mediatization phenomenon and its influence on the way companies relate with contemporary society. It also attempts to perceive how in this process organizational discourse becomes impregnated with traces of the interlocutor with who it tries to relate, as well as of socio-cultural reality.

KEYWORDS: MEDIATIZATION • ORGANIZATIONAL DISCOURSE • CONTEMPORARY CULTURE

Resumen

Se busca, por medio del análisis de un canal televisivo de marca, el canal Oi, comprender el fenómeno de la mediatización y sus reflejos en la manera como las empresas se relacionan con la sociedad en la contemporaneidad. Se pretende, asimismo, entender como el discurso organizacional, en este proceso, se impregna de rasgos del interlocutor con el cual se pretende relacionar y de la realidad sociocultural.

PALABRAS CLAVE: MEDIATIZACIÓN • DISCURSO ORGANIZACIONAL • CULTURA COMTEMPORÁNEA 
A experiência do homem no mundo contemporâneo é marcada pela convivência com as organizações - em especial as empresariais. Como sujeitos sociais, estas organizações são transformadas pelas mudanças na sociedade da mesma forma que transformam a sociedade a partir de suas ações. Por esta perspectiva, o contexto organizacional não pode ser entendido como esfera independente da sociedade, mas, pelo contrário, como integrante do tecido social, configurando-se como privilegiado ângulo de análise dos fenômenos sociais mais amplos.

Neste estudo, apresentamos as organizações privadas como sujeitos constituintes de um campo social relativamente autônomo, que é o empresarial. Neste sentido, embora não constituam uma esfera independente da sociedade, aceita-se que gozam de alguma autonomia, exercendo certas funções específicas. Para o entendimento de seus processos legitimadores, resgatamos a noção de campo social de Bourdieu (1983), cujo trabalho busca entender as relações de força e os processos regulatórios da sociedade, e para quem o mundo social é uma formação composta por diferentes espaços de relações, os campos sociais.

$\mathrm{Na}$ organização da sociedade contemporânea, assistimos ao processo de articulação dos campos sociais (político, jurídico, acadêmico, etc) ao campo da mídia, dado sua função de mediação social. Ou seja, é justamente por deter esta propriedade que o campo dos media se distingue dos demais ao mesmo tempo em que, através da crescente demanda por mediação dos outros campos, ocupa um papel central na constituição da sociedade contemporânea (RODRIGUES, 1997). O processo de apropriação da lógica midiática por outros campos sociais recebe, de autores como Barichello (2008), Braga (2006) e Sodré (2002), o nome de midiatização.

Podemos dizer que, na contemporaneidade, a principal esfera de mediação social é a mídia, através da qual todos os campos interagem e competem por visibilidade, na busca por legitimação. A noção de legitimação precisa ser entendida como diretamente relacionada à questão da publicização e da visibilidade pública, o que, nos dias atuais, ocorre no campo da mídia. Assim, a esfera midiática é condição sine qua non para a justificação social de todos os demais campos, é a esfera onde se torna possível legitimar sua atuação (RODRIGUES, 1997).

A partir da perspectiva das empresas, percebemos que elas também tentam legitimar sua atuação através da visibilidade midiática, passando a operar segundo a lógica da mídia - fenômeno que passamos a denominar midiatização empresarial. Para isto, utilizam-se notadamente de duas estratégias de interação com a sociedade: a interação através de meios de comunicação de massa e a interação através das mídias organizacionais. Por meios de comunicação de massa, entendemos os veículos rádio, televisão e a imprensa - sendo que a interação por estes meios se dá essencialmente a partir da veiculação de anún- 
cios (publicitários ou institucionais); e, por mídias organizacionais, entendemos os veículos que "utilizam os suportes tecnológicos advindos dos meios de comunicação de massa (rádio, televisão e imprensa), mas [que] são totalmente gerenciados pelas organizações privadas de diferentes setores" (FOSSÁ; SGORLA, 2008, p. 2), como os house organs e os vídeo institucionais, por exemplo.

O desenvolvimento e a utilização destas estratégicas de interação para legitimar a atuação organizacional segue os passos evolutivos da própria sociedade. À medida que a sociedade evolui, aprimora suas possibilidades de interação, de modo que o impacto da globalização e o incremento das tecnologias digitais, que caracterizam o contexto contemporâneo, são conformadores de novos discursos, modos de relacionamento social e formas de representação das empresas no espaço midiático - ou seja, novos modos de buscarem legitimação.

"Atualmente, a lógica midiática tem perpassado os outros campos sociais num processo conhecido como midiatização. Nesse processo, a comunicação das instituições cada vez mais se utiliza de estratégias provenientes do campo dos mídia para articular a sua interação com os públicos. Possibilitadas pelas novas tecnologias, elas geram novas formas de sociabilidade, modificam antigas formas de relacionamento, criam situações diferenciadas para a ação e interação, reestruturando, portanto, as relações existentes entre as organizações e a sociedade." (BARICHELLO, 2008, p. 240).

Por esta perspetiva, e considerando que também os processos interacionais no contexto organizacional têm acompanhando o movimento de midiatização da sociedade, percebemos como as práticas de comunicação empreendidas pelas empresas têm se transformado e ido além da perspectiva de anunciantes nos meios de comunicação de massa ou de criadores de mídias organizacionais, tal como antes as concebíamos. Se, tradicionalmente, estas práticas resumiamse às ações de publicidade e propaganda, jornalismo empresarial ou relações públicas, materializadas em veículos de comunicação direcionados a públicosalvo (jornais de empresa, folders, outdoors etc.), percebemos que, num cenário marcado pela convergência tecnológica e globalização, pautado pela lógica do consumo, as interações empresariais também tornam-se líquidas - para utilizarmos o conceito pelo qual Bauman (2001) descreve o mundo contemporâneo.

Concretamente, o reflexo disto pode ser percebido na tendência das organizações em também tornarem-se mídia, por meio de ações de comunicação em que deixam de ser anunciantes ou produtoras de mídias organizacionais para se tornarem, elas próprias, produtoras de conteúdo cultural, como por meio da criação de revistas customizadas ou eventos de experiência de marca. Nestas ações, percebemos que as organizações levam o conceito de mídias organizacionais ao extremo, não mais divulgando seus produtos em veículos de comunicação (próprios ou não), nem patrocinando eventos renomados, de modo a associarem suas marcas a eles, mas tornando-se mídia, transformando-se em seus próprios veículos, e sendo o seu próprio evento. Nestas ações, 
percebemos menos a presença de uma mensagem que precisa ser transmitida e mais a tentativa de um enquadramento da interação pelo partilhamento de um quadro de referências simbólicas (como estilos de vida, valores, atitudes) que interpela sujeitos para uma relação - e a partir do qual sentidos, discursos e identidades serão criados cooperativamente.

Desta maneira, entendemos que o campo midiático configura-se como instância de realização, por excelência, de estratégias de visibilidade do campo empresarial, com vistas a legitimar-se. Mais, configura-se como uma possibilidade concreta de inserção de atores e relações privadas na esfera pública.

\section{Canal Oi como estratégia de legitimação e interação com a sociedade}

O Canal Oi, transmitido 24 horas pelo canal 31 da Oi TV (operadora a cabo), em algumas cidades do estado de Minas Gerais, inscreve-se no rol de ações empreendidas pela empresa Oi, a maior operadora de telecomunicações do Brasil em faturamento, segundo website da empresa ${ }^{1}$, para se relacionar com a sociedade. A Oi oferece serviços de telefonia fixa, telefonia móvel, comunicação de dados, internet e televisão por assinatura, além de disponibilização de conteúdo multiplataforma para ser visto onde, quando e como o usuário quiser. Um dos objetivos declarados da empresa é oferecer o que há de mais avançado em telecomunicações e, para isto, ela investe na construção de uma imagem organizacional arrojada, apostando na interlocução preferencial com o público jovem.

Maffesoli (2004) nos ajuda a entender a centralidade da figura do jovem na contemporaneidade, o que também explica porquê ela se configura como um dos principais argumentos discursivos dos sujeitos ditos pós-modernos (incluindo as organizações). Em sua análise, o autor utiliza-se das figuras emblemáticas da modernidade e da pós-modernidade, marcando uma diferença entre as duas formações socioculturais. Segundo ele, a figura emblemática da modernidade seria o homem adulto e sério, o pai de família bem sucedido financeiramente, que todos deveriam querer ser, uma projeção para um futuro glorioso, um herói. Já a figura da pós-modernidade seria de uma eterna criança ou do jovem hedonista, eternamente enraizado no presente, numa juventude que, devido à sua sensualidade aguçada, todos querem e podem ter.

Pais (2006) reforça que, na contemporaneidade, nem mesmo se pode falar de uma passagem obrigatória à vida adulta, já que se abrem possibilidades de prolongamento indeterminado da juventude, numa temporalidade que não suprime o tempo linear (a progressão rumo a um futuro), mas o complexifica, fazendo do futuro um espaço de múltiplas possibilidades de retorno. O autor vale-se do exemplo do casamento para ilustrar seu ponto de vista: se, antes,

1 Disponível em: <http://www.novaoi.com.br>. Acesso em: 20 dez. 2008. 
este era um acontecimento para a vida toda, hoje, casa-se já se considerando a possibilidade do divórcio, ou seja, a possibilidade de retorno à condição de solteiro e a abertura para novos começos. Dessa forma, mais do que dizer de uma faixa etária, o termo juventude passa a dizer de um valor da cultura contemporânea, de uma condição e uma escolha possíveis. Por isto, o discurso jovem configura-se como uma estratégia de interação que integra o processo de construção identitária possível a todos os sujeitos contemporâneos.

O Canal Oi estrutura-se a partir de um discurso jovem, tomando como principal ponto de referência o universo musical: a programação gira em torno dos videoclipes de músicas pop ${ }^{2}$, intercaladas por vinhetas e alguns programas. $O$ videoclipe é utilizado não apenas como material de veiculação, mas como linguagem. Isto significa que não apenas evocam um universo simbólico a ser compartilhado (e consumido) com os jovens, como são eles que imprimem ritmo ao fluxo da experimentação proposta pelo canal: um ritmo rápido, agitado, fragmentado. Uma linguagem que estará presente também nas suas vinhetas e programas.

\section{O Canal Oi como um canal televisivo de marca}

Ao tomarmos o Canal Oi como proposta de interação da empresa Oi com a sociedade, entendemos tratar-se de uma ação desenvolvida com o objetivo de criar uma identidade de marca para a Oi - razão pela qual o designamos como um canal televisivo de marca. Entendemos, assim, que o Canal Oi configurase como uma ação emblemática do processo pelo qual uma empresa passa a operar pela lógica midiática, inserindo-se e buscando legitimar-se na esfera pública através da veiculação de conteúdo produzido ou gerenciado pela própria empresa, num canal de TV a cabo.

O Canal Oi está inserido na grade de canais disponíveis aos assinantes da TV a cabo Oi TV. Trata-se, portanto, de uma mídia segmentada, inserida num meio de comunicação massivo ${ }^{3}$ - a televisão. Este canal apresenta outras peculiaridades, sendo a principal constituir-se num canal de marca, na medida em que busca promover os aspectos simbólicos ligados à identidade da marca Oi. Esta construção baseia-se fundamentalmente em elementos do universo jovem, buscando incorporá-los no discurso e processos de significação que envolvam a marca Oi.

2 Tomamos aqui a definição de Jianotti Júnior (2008, p. 206), para quem a música pop corresponde à música popular midiática, ou seja, "a música produzida, fixada ou difundida de forma massiva."

3 Não é objetivo deste trabalho discutir se a televisão é ou não um meio de comunicação de massa. Ao usarmos o termo massivo estamos chamando a atenção para uma das características mais gerais da TV aberta - a abrangência e a indiferenciação de seu público - em contraste com a segmentação possível da TV a cabo. Sabemos, contudo, que esta abstração obscurece o entendimento dos processos concretos de recepção que podem se dar tanto na TV aberta, quanto na TV por assinatura. 
Percebemos que a empresa Oi configura-se simultaneamente como proprietária da emissora e sua única anunciante. O que se anuncia, no entanto, tanto nos intervalos comerciais quanto na composição da programação, são estilos de vida e valores sob os quais se deseja construir uma identidade de marca - e não os produtos e serviços que a empresa comercializa. Tampouco outros produtos, de outras empresas, são anunciados. Mas, para além de configurar-se como uma estratégia de comunicação empresarial, o Canal Oi é também um produto da empresa Oi. Somente os assinantes de seu serviço de TV a cabo têm acesso a ele, de modo que seu público, também, é constituído somente pelos consumidores de um de seus serviços - os de TV a cabo.

Assim, embora o Canal Oi seja propriedade de uma empresa de telecomunicações, a Oi, esta não o utiliza como fonte de captação de recursos (com a venda de anúncios publicitários para outras empresas), nem como canal promocional (com a veiculação de anúncios promocionais sobre a venda de seus próprios produtos e serviços), nem mesmo como um canal de programação (que apresenta a grade de programas dos demais canais disponíveis aos assinantes do serviço de televisão a cabo). Trata-se de um canal que veicula um tipo bastante específico de material institucional, aquele que se relaciona com o universo simbólico que a marca se apropria para falar de si.

\section{Os dispositivos de enunciação do Canal $0 \mathrm{i}$}

Para alcance do objetivo proposto, qual seja o de compreender os modos pelos quais uma organização passa a operar pela lógica midiática para se relacionar com a sociedade, adotou-se uma metodologia qualitativa composta de uma pesquisa bibliográfica e uma investigação empírica. Nesta última, o Canal Oi foi analisado a partir de seus dispositivos de enunciação (VERÓN, 2004; MARTÍN-BARBERO, 2008), por meio dos quais buscamos perceber tanto a imagem que a Oi tenta construir de si quanto a que cria de seus interlocutores, bem como, ainda, a proposta de interação que é colocada - conformada pelas balizas maiores da cultura contemporânea.

Nosso corpus de análise foi composto por 24 horas de programação do Canal Oi, distribuídas da seguinte forma:

Figura 1: Quadro descritivo do corpus definitivo

\begin{tabular}{|c|c|c|c|c|c|c|c|}
\hline $\begin{array}{c}\text { Fita } 1 \\
\text { Estréia do } \\
\text { Canal } 0 \mathrm{i}\end{array}$ & Fita 2 & Fita 3 & Fita 4 & Fita 5 & Fita 6 & Fita 7 & Fita 8 \\
\hline $15 / 04 / 2008$ & $16 / 08 / 2008$ & $17 / 08 / 2008$ & 18/08/2008 & $19 / 08 / 2008$ & $20 / 08 / 2008$ & 21/08/2008 & $22 / 08 / 2008$ \\
\hline 19 às $22 \mathrm{~h}$ & 00 às $03 \mathrm{~h}$ & 06 às $09 \mathrm{~h}$ & 12 às $15 \mathrm{~h}$ & 18 às $21 \mathrm{~h}$ & 00 às $03 \mathrm{~h}$ & 06 às $09 \mathrm{~h}$ & 12 às $15 \mathrm{~h}$ \\
\hline
\end{tabular}


Após levantamento de um panorama histórico sobre o contexto de surgimento da Oi e do Canal Oi no cenário brasileiro, foi realizado um trabalho de caracterização descritiva sobre a estruturação de conteúdo na programação do Canal para, a partir daí, procedermos ao exame de seus dispositivos de enunciação.

Em termos de estrutura de programação, sabemos que, embora a grade seja composta de fragmentos diversos e híbridos, ela é experimentada pelo telespectador como um fluxo (WILLIAMS, 1975). Para isto, o material veiculado precisa encontrar coerência numa identidade que vai ser usada como argumento de interpelação. Em outras palavras, um canal televisivo tende a ser mais bemsucedido quanto mais clara for sua unidade discursiva, ou seja, quanto maior sua capacidade de criar identificação com seus interlocutores numa matriz de significação compartilhada. Como reforça Duarte (2004, p. 45),

"as emissoras falam de si através de suas programações. Partindo da pressuposição de existência de intencionalidade em qualquer ato comunicativo, evidencia-se a responsabilidade da emissora pelas escolhas de programas e de encadeamentos, que, evidentemente, não são arbitrárias. Tais escolhas, aliás, são fortes componentes da construção da identidade de uma emissora enquanto ser do mundo."

Como pudemos perceber, a seleção musical - de artistas e videoclipes - do Canal Oi obedece a uma lógica de mercado, enfocando os hits da música pop, como numa rádio FM. A escolha por certos gêneros parece importante para afirmar as preferências da Oi, uma forma de expressão de sua identidade. Enquanto o rock, o hip-hop e até o reggae encontram seu espaço no Canal, o sertanejo, samba, axé, pagode e a música clássica são exemplos de gêneros musicais que não fazem parte da programação. A seleção destes gêneros musicais nos pareceu fundamental para uma primeira definição da proposta de interação do Canal Oi, que, assim, dirige-se a um determinado tipo de interlocutor: o jovem que valoriza o tempo de hoje (músicas que estão no topo das paradas de sucesso) e que é mais cosmopolita (músicas internacionais, rock, hip-hop) do que regionalista (sertanejo, samba, axé, pagode).

Ao adotar uma linha que prioriza os hits FM, o Canal Oi privilegia a produção de artistas estrangeiros cujo conteúdo de seus videoclipes reforçam marcadamente os ideais de consumo: o intérprete como uma celebridade, retratado num mundo glamourizado e invarivelmente bem-produzido. Destacam-se ainda as performances que são acompanhadas por passos de dança coreografados, permitindo que os fãs reproduzam todo o gestual de seus ídolos.

Como nosso esforço de análise objetivou perceber a relação que se estabelece a partir do Canal Oi, ou seja, os modos pelos quais a empresa se enuncia e interpela seus interlocutores, foi empreendida uma análise qualitativa do corpus. Para organizar nossa leitura da proposta de interação do Canal Oi, adotamos categorias analíticas inspiradas na proposta de dispositivos de enunciação, de 
Martín-Barbero (2008), capazes de indicar, em quatro níveis de análise, o modo como o leitor (ou o telespectador) é incorporado já na produção do texto (ou do programa televisivo). Foram elas:

1. os dispositivos de composição visual - compreendendo os graphics, ou seja, todos os recursos visuais (logomarca, design gráfico, legenda, logotipos), destinados a construir a identidade visual do Canal Oi;

2. os dispositivos de fragmentação da leitura ${ }^{4}$ - compreendendo principalmente o uso das vinhetas no Canal Oi, entendidas como responsáveis por, ao dividir a programação em blocos, também promover sua articulação, conferindo certa unidade ao canal e estruturando o fluxo proposto para a experiência do espectador;

3. os dispositivos de sedução - compreendendo o uso de um tipo específico de vinhetas, que são as utilizadas como chamadas para sua programação, ou seja, as vinhetas que funcionam como propaganda dos próprios programas do Canal Oi e que possuem, mais explicitamente, uma materialização do espectador pretendido por serem uma espécie de convite, um convite que é sempre dirigido a;

4. os dispositivos de reconhecimento - em nossa análise, compreendem a identificação dos principais conceitos, temáticas e valores invocados pelo Canal Oi, ou seja, quais são os elementos e como o canal trabalha o quadro simbólico compartilhado com seus interlocutores e a sociedade em que se inserem.

\section{Dispositivos de composição visual}

Os elementos gráficos utilizados pelo Canal Oi não deixam dúvidas quanto à sua proposta de interação e inserção no universo de referência jovem. Os grafismos são um dos principais pontos de construção da identidade visual do canal. A logomarca da empresa Oi, por sua vez, é incorporada na logomarca do Canal Oi, de modo que a análise de uma remete necessariamente à outra. Assim, adota como nome uma expressão corriqueira de nosso idioma - que indica uma interjeição de saudação informal -, utiliza como representação gráfica uma amebóide e ainda apresenta seis possibilidades de aplicação desta logomarca.

"A logomarca da Oi expressa uma forma direta e informal de dizer "oi". Cada pessoa tem seu jeito de dizer "oi", portanto, não existe uma forma única para a logomarca. Por este motivo foram criados seis formatos que refletem essa flexibilidade. Não se trata da tradicional logomarca que assina um anúncio, mas de uma marca que participa de forma central na comunicação. Mais do que uma

4 Falamos de leitura de maneira alargada, apoiando-nos na idéia de texto como qualquer tipo de manifestação material, seja oral, visual, gráfica, gestual, icônica etc. (CHARADEAU, 2008). 
assinatura, criamos uma linguagem, e a logomarca é parte fundamental desse jeito de se comunicar." (OI, $s / d, s / p)$.

Na busca pela padronização de seus materiais, a Oi investe numa linguagem gráfica que torna taxativo o uso de certas cores: o amarelo na logomarca; e o azul, laranja ou lilás como fundo. A idéia de utilizar sempre um fundo que remeta às cores da empresa parecem ilustrar exatamente a perspectiva de Klein (2002) de que as marcas, na contemporaneidade, vão metamorfoseando tudo à sua volta. As pessoas e situações retratadas em seu material de comunicação estão sempre camufladas nas cores da empresa, indicando, numa hierarquia de importância, o referencial que deve se sobressair. Ou seja, indicam a tentativa de imprimir a significação desejada pela marca sobre o quadro de sentido de seus interlocutores.

\section{Dispositivos de fragmentação da leitura}

Além do principal produto veiculado pelo Canal Oi ser o videoclipe, percebemos que sua linguagem extrapola seu momento de veiculação. O canal utilizase de suas técnicas de edição rápida, não linearidade e distorções na relação espaço e tempo para construção de uma linguagem própria. Assim, os videoclipes são exibidos sequencialmente, dispensando a figura de um apresentador ou $V J^{5}$ que os narre aos telespectadores. E, entre os clipes, aparecem as vinhetas e alguns programas.

As vinhetas podem ser consideradas como elemento estruturador da interação e experiência que se pretende estabelecer com o telespectador; como o elemento que, de certa forma, ordena os blocos de videoclipes e programas em uma sequência. Neste sentido, acreditamos que se configuram como dispositivos de fragmentação de leitura que já trazem traços que remetem ao interlocutor jovem.

Pela análise de nosso corpus, classificamos as vinhetas em cinco categorias: a vinheta de apresentação, as vinhetas interativas, as vinhetas videoclipe, as vinhetas de homenagem e as vinhetas de programas.

- Vinheta de apresentação: veiculada na fase de estréia do Canal Oi, sintetizando sua proposta;

- Vinhetas interativas: veiculadas nas passagens de um clipe ao outro, anunciando o clipe que será apresentado na sequência. Trata-se de um serviço

5 VJ é a abreviação de video jockey. Como os DJs, ou disc jockeys - responsáveis por misturar músicas diferentes, produzindo um set musical contínuo -, os VJs são os profissionais que vão ao ar para anunciar os videoclipes que serão exibidos, comentá-los, se apresentar como os porta-vozes da emissora e, de maneira simbólica, inserir o videoclipe numa sequência discursiva. 
$\mathrm{SMS}^{6}$ em que o telespectador é convocado a acessar o Portal Oi, na internet, para obter mais informações sobre o conteúdo do Canal Oi;

- Vinhetas videoclipe: apropriação de trechos dos próprios clipes veiculados, desconstruindo-os e reelaborando-os a partir do que seria a linguagem do Canal Oi;

- Vinhetas de homenagem: gravações com a saudação de artistas nacionais ao Canal Oi;

- Vinhetas de programas: veiculadas na abertura e encerramento dos programas.

A vinheta de apresentação do Canal Oi merece destaque não apenas como a primeira a ser veiculada, mas principalmente por carregar a apresentação institucional do Canal e imagens de seus diversos programas. Por esta perspectiva, entendemos que os elementos essenciais para abordagem dos valores organizacionais, bem como a proposta de interação que o Canal Oi pretende engendrar, estão mais visíveis neste material.

A vinheta de apresentação enfatiza, através de grafismos na tela, os temas: música, tecnologia, artes e informação, todos relacionados ao universo jovem, definindo a diretriz dos conteúdos veiculados pelo Canal $\mathrm{Oi}$ - o que corresponderia a uma linha editorial, para o caso de uma publicação. Nas imagens, apenas jovens (numa acepção etária) são apresentados, em momentos de descontração e divertimento. Pela locução, percebemos um esforço de articulação das temáticas num mesmo quadro de referência. Ou seja, por esta vinheta percebemos como, num mundo que parece se pautar pela alta velocidade (como aponta a sobreposição de imagens da vinheta, como num videoclipe), o Canal Oi se coloca como um articulador e organizador dos temas de interesse do jovem. Mais, enfatiza o aspecto da interatividade e solicita a interação do interlocutor, quando coloca como lema: "Canal Oi, interaja conosco".

As vinhetas interativas antecedem sempre a veiculação dos videoclipes, fazendo a passagem de um para outro. Assim, dispensando a presença de um VJ, o Canal Oi aposta numa certa autonomia do telespectador para a leitura de seu material. Saem portanto os VJs e entram as vinhetas interativas, com uma proposta de interatividade midiática através de mecanismos tecnológicos que fazem parte do conjunto de serviços convergentes da empresa Oi. Como apresentado, trata-se de um serviço SMS em que, ao interagir com o Canal, o usuário gera mais receita para a empresa, sendo levado a utilizar seus serviços convergentes.

$\mathrm{Na}$ análise das vinhetas videoclipe, percebemos que estas aparecem como o material mais visualmente elaborado do canal, trabalhando a partir da identi-

6 SMS é a abreviação de Short Message Service, que corresponde a um protocolo de comunicação que permite a troca de pequenas mensagens de texto entre telefones celulares. Na linguagem jovem, é 0 chamado torpedo. 
dade visual adotada pela empresa em suas outras frentes de ação, como em peças gráficas e no website. As vinhetas foram criadas a partir de trechos de videoclipes que são desconstruídos, por meio de recursos de editoração multimídia, adulterando a relação original de tempo e espaço. As imagens parecem desincronizadas em relação ao áudio, ora um ora outro se adiantando ou atrasando em relação ao material original. Ao final, encerra-se a vinheta com o congelamento da tela no ícone pop, o artista do videoclipe utilizado, sob a logomarca da Oi.

Nas vinhetas videoclipe, percebemos uma tentativa de personificação da marca e da imagem do Canal Oi através dos ícones pop que estão por trás dos videoclipes exibidos. No entanto, para além desta observação, percebemos a incorporação da linguagem videoclipe - narrativa não-linear, edição rápida, sobreposição de imagens, descolamento das dimensões de tempo e espaço - trabalhando o próprio material videoclipe. Ou seja, as vinhetas têm como material base o videoclipe de artistas pop e faz uso de recursos de edição para brincar, a partir das mesmas técnicas desta linguagem, com o material utilizado. Assim, evidencia-se a noção de que o material veiculado não são obras prontas e intocáveis mas, pelo contrário, constituem-se como materiais disponíveis para a manipulação, apropriação e resignificação pela Oi e por seus interlocutores, presumidamente habituados com as tecnologias de interação e de intervenção - remetendo à estética da bricolagem, uma característica marcante do tempo pós-moderno.

Já as vinhetas de homenagem correspondem a gravações feitas com artistas nacionais saudando a criação do Canal Oi. Nestas vinhetas, percebemos uma tentativa de avalizar as ações do Canal Oi através do apoio de artistas. Ao veicular os cumprimentos e apoio recebidos pela classe artística, o Canal Oi oferece indícios de sua relevância enquanto instrumento de fomento à cultura e à interatividade. Este tipo de articulação evidencia, de maneira bastante explícita, a necessidade de legimitimação do canal.

Por fim, temos as vinhetas de programas que são o material utilizado na abertura e encerramento dos programas, conferindo elementos identitários ao material - funcionando como a capa para um livro, por exemplo. Em nossa análise, percebemos que os mesmos elementos destas vinhetas estão presentes nas vinhetas que fazem chamadas para os programas, sendo então enquadradas como dispositivos de sedução.

\section{Dispositivos de sedução}

Em nossas análises, destacamos numa categoria distinta as vinhetas de chamada de programas, que funcionam como propaganda da própria programação. Estas são consideradas dispositivos de sedução porque têm como principal objetivo atrair a atenção e despertar o interesse do telespectador para que assista 
aos programas do Canal Oi. Neste esforço, percebemos de maneira mais evidente a tentativa de inserção do quadro de referências simbólicas do interlocutor jovem no material veiculado.

Pelas análises empreendidas, cujo amplo detalhamento não é possível ser reproduzido neste espaço, pudemos perceber que a aproximação dos programas a determinados gêneros, estéticas e temáticas, e a escolha por cada um deles cinema, game, música, notícia, esportes, moda, viagem - não é obra do acaso. Trata-se de mecanismos que orientam a leitura do material, direcionando-a a propostas de significação específicas. Como nos lembra Martín-Barbero (2008, p. 189), gênero pode ser entendido "como um lugar exterior à 'obra', a partir de onde o sentido da narrativa é produzido e consumido, ou seja, lido e compreendido (...)". A construção da identidade jovem na contemporaneidade passa por estas arenas - cinema, game, música, notícia, esportes, moda, viagem - e o uso deste tipo de dispositivo pelo Canal Oi visa não apenas atrair o jovem como interlocutor preferencial como enquadrar sua produção de sentido.

\section{Dispositivos de reconhecimento}

Por fim, analisamos a proposta de interação do Canal Oi por meio dos principais conceitos, temáticas e valores percebidos como invocados em sua programação - e que remetem ao universo de seu interlocutor: o jovem - ainda que de espirito. Segundo a proposta de Martín-Barbero (2008, p. 185), na qual nos inspiramos, os dispositivos de reconhecimento correspondem àqueles elementos que permitem ao interlocutor se perceber na obra, ou seja, aqueles que mostram como "o mundo do leitor é incorporado ao processo de escritura e nela penetra deixando seus traços no texto”.

Na vinheta de apresentação, percebemos que a interpelação do interlocutor dá-se pela consideração de que este é um sujeito familiarizado com as novas tecnologias digitais - e, portanto, que domina as técnicas de manipulação e colagem de material -, investindo numa proposta de naturalização das técnicas da bricolagem. Apresenta-se, então, o Canal Oi como o ponto de encontro e articulação entre música, games, tecnologia, comportamento, artes, notícia e interação, propondo que todas estas esferas relacionam-se entre si, mais uma vez, evidenciando a noção de convegência que norteia as ações da empresa Oi.

Já nas vinhetas interativas, a interpelação aparece como uma proposta clara de interação, ou seja, como um convite ao contato. Percebemos, nesta abordagem, que tanto considera-se que existe um quadro de referências definido e compartilhado entre o interlocutor e o Canal Oi (expresso na seleção dos videoclipes dos artistas e temáticas dos programas, por exemplo) como que este vínculo aproxima os interlocutores (como se o Canal Oi conhecesse os gostos individuais dos telespectadores e montasse sua programação a partir deles). Desta forma, o reconhecimento por parte do interlocutor, mesmo vindo de 
uma abordagem genérica, dá-se no âmbito de um universo específico: o universo jovem com o qual, pretende-se, o interlocutor irá se identificar.

As vinhetas videoclipe, por sua vez, permitem reconhecimento tanto a partir do uso da imagem e música dos artistas (que estão por trás dos videoclipes exibidos), como pela linguagem adotada. É preciso que o interlocutor seja familiarizado no universo da música pop para que reconheça os ídolos retratados e sua música, já que esta sofre efeitos de distorção em relação à versão original. Mais uma vez, a linguagem utilizada apoia-se na técnica de bricolagem, em que o videoclipe serve de material para novas apropriações, sendo recontextualizado pelo quadro de referências do Canal Oi.

Já nas vinhetas de homenagem constituem dispositivo de reconhecimento por trazerem a imagem dos artistas validando a proposta do Canal Oi. A efetividade do dispositivo estaria, então, no reconhecimento, por parte dos telespectadores, de que os artistas são celebridades que gozam de prestígio suficiente para empregar sua imagem em prol de uma ação (promocional) destas.

Por fim, temos, nas vinhetas de programas, modos de interpelação que remetem ao domínio de um repertório próprio aos mundos da música, cinema, games, moda, tecnologia, turismo - permitindo, assim, o reconhecimento por parte dos interlocutores.

A partir destes dispositivos, percebemos como o interlocutor do Canal Oi, descrito genericamente, por uma perspectiva sociológica mais rígida, como um sujeito pertecente a determinada classe social, determinada faixa etária e com determinados hábitos e costumes, pode ser descrito também como uma realidade discursiva. Trata-se de um entendimento crucial para o campo da comunicação no contexto organizacional, que tende a denominar público como uma entidade para quem a organização direciona suas ações. Por este outro ponto de vista, o interlocutor organizacional é um sujeito que já se encontra presente nas formas de interação engendradas pelo produtor do discurso e que pode ser lido pelas marcas que deixa nas propostas de interação. O público-alvo real inexiste, portanto, de antemão. Ele é conformado na medida em que aceita a convocação e passa a negociar significados em uma relação que abrange o material simbólico oferecido e um quadro de referência cultural.

\section{Considerações finais}

Nossas análises apontaram para o reconhecimento de que o esforço da empresa Oi tornar-se mídia deve-se, em grande parte, à centralidade que esta ocupa nos processos legitimatórios da contemporaneidade. O Canal Oi mostrou-se um caso exemplar de branding avançado, como possibilidade de construção de uma identidade de marca a partir de um quadro simbólico que se mostra e se renova no fluxo de um canal de televisão. Se a identidade é uma construção 
permanente, a perspectiva de enunciá-la e desenvolvê-la num veículo midiático parece ser emblemática para o entendimento da constituição dos sujeitos contemporâneos (incluindo as organizações).

Nossas análises indicaram ainda que o Canal Oi toma como quadro de referência o jovem e que, através de suas ações comunicacionais, a empresa constrói um discurso e uma representação do que é ser jovem na contemporaneidade. Ser jovem, para a Oi, parece ser compartilhar de um universo simbólico, mais do que pertencer a uma faixa etária. E é a partir destas referências - ancoradas na música, tecnologia, comportamento, informação e interatividade - que a marca constrói sua identidade e interpela seus interlocutores. Acreditamos que o estudo do fenômeno da midiatização neste contexto específico, que é o organizacional, aponta para uma importante tendência de pesquisa na área, a partir de uma reflexão diferenciada sobre o fenômeno.

\section{Referências}

BARICHELLO, Eugênia M. R. Apontamentos em torno da visibilidade e da lógica de legitimação das instituições na sociedade midiática. In: DUARTE, Elizabeth B; CASTRO, Maria Lília D. (Orgs.). Em torno das mídias: práticas e ambiências. Porto Alegre: Sulina, 2008. p. 237-249.

BAUMAN, Zigmunt. Modernidade líquida. Rio de Janeiro: Zahar, 2001. . Vida para consumo: a transformação das pessoas em mercadorias. Rio de Janeiro: Zahar, 2008.

BOURDIEU, Pierre. Questões de sociologia. São Paulo: Ática, 1983.

BRAGA, José Luiz. Mediatização como processo interacional de referência [Grupo de Trabalho Comunicação e Sociabilidade]. In: ENCONTRO ANUAL DA ASSOCIAÇÃO NACIONAL DOS PROGRAMAS DE PÓS-GRADUAÇÃO EM COMUNICAÇÃO (COMPÓS), 15., 2006, Bauru. Anais... Bauru: Universidade Estadual Paulista, 2006. 1 CD-ROM.

CHARADEAU, Patrick. Linguagem e discurso: modos de organização. São Paulo: Contexto, 2008.

DUARTE, Elizabeth Bastos. Televisão: ensaios metodológicos. Porto Alegre: Sulina, 2004.

ESTEVES, João Pissarra. A ética da comunicação e os media modernos: legitimidade e poder nas sociedades complexas. Lisboa: Fundação Calouste Gulbenkian, 1998.

FOSSÁ, Maria Ivete; SGORLA, Fabiane. A visibilidade midiática das práticas de responsabilidade social como estratégia de legitimação organizacional [NP Relações Públicas e Comunicação Organizacional]. In: CONGRESSO BRASILEIRO DE CIÊNCIAS DA COMUNICAÇÃO. 31., 2008, Natal. Anais... Natal: Intercom, 2008.

FRANÇA, Vera V. Sujeitos da comunicação, sujeitos em comunicação. In: GUIMARÃES, César; FRANÇA, Vera (Orgs.). Na mídia, na rua: narrativas do cotidiano. Belo Horizonte: Autêntica, 2006. p. 61-88.

HOLT, Douglas B. Why do brands cause trouble? A dialectical theory of consumer culture and branding. Journal of Consumer Research, Chicago, v. 29, p. 70-90, 2002.

JIANOTTI JÚNIOR, Jeder. Gêneros musicais e comunicação: proposição de um modelo de análise midiática da música popular massiva. In: DUARTE, Elizabeth B; CASTRO, Maria Lília D. (Orgs.). Em torno das mídias: práticas e ambiências. Porto Alegre: Sulina, 2008. p. 205-222.

KLEIN, Naomi. Sem logo: a tirania das marcas em um planeta vendido. Rio de Janeiro: Record, 2002.

KUNSCH, Margarida Maria Krohling. Planejamento de Relações Públicas na Comunicação Integrada. 4. ed. São Paulo: Summus, 2003.

MAFFESOLI, Michel. Perspectivas tribais ou a mudança do paradigma social. Revista Famecos, Porto Alegre, n. 23, p. 23-29, abr. 2004.

MARTíN-BARBER0, Jesús. Dos meios às mediações: comunicação, cultura e hegemonia. 5. ed. Rio de Janeiro: Editora UFRJ, 2008.

O'GUINN, Thomas C.; ALLEN, Chris T.; SEMENIK, Richard J. Propaganda e promoção integrada da marca. São Paulo: Cengage Learning, 2008.

Ol. Manual da marca. s/d. Mimeografado. 
PAIS, José Machado. Buscas de si: expressividades e identidades juvenis. In: ALMEIDA, Maria Isabel Mendes de; EUGENIO, Fernanda (Orgs.). Culturas Jovens: novos mapas do afeto. Rio de Janeiro: Jorge Zahar, 2006.

RODRIGUES, Adriano Duarte. Estratégias da comunicação: questão comunicacional e formas de sociabilidade. 2. ed. Lisboa: Editorial Presença, 1997.

SCHULTZ, Majken; ANTORINI, Yun Mi; CSABA, Fabian F. (Orgs.). Corporate Branding: Purpose/People/Process. Copenhagen: Copenhagen Business School Press, 2005.

SODRÉ, Muniz. Antropológica do espelho: uma teoria da comunicação linear e em rede. Petrópolis: Vozes, 2002.

VERÓN, Eliseo. Fragmentos de um tecido. São Leopoldo: Editora Unisinos, 2004.

WILLIAMS, Raymond. Television: technology and cultural form. Nova lorque: Schocken Books, 1975. 